\title{
The effect of human serum on the efficacy of traditional antifungals against Candida
} albicans and Candida parapsilosis biofilms

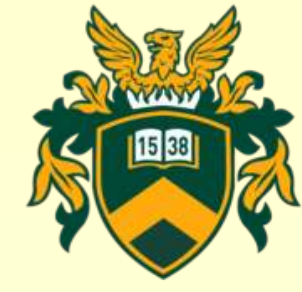

UNIVERSITY of DEBRECEN

\author{
$\underline{\text { Renátó Kovács }}{ }^{1}$, Fruzsina Nagy $^{1}$, Zoltán Tóth ${ }^{1}$, Aliz Bozó ${ }^{1}$, László Majoros ${ }^{1}$
}

${ }^{1}$ Department of Medical Microbiology, Faculty of Medicine, University of Debrecen, Hungary

Objectives: To extend our knowledge about the in vitro anti-biofilm activity of the most frequently used traditional systemic antifungals (fluconazole, amphotericin B, caspofungin, micafungin), their activity was compared in RPMI-1640 and RPMI-1640 plus 50\% human serum against Candida albicans and $C$. parapsilosis biofilms to mimic better the in vivo conditions.

Material and methods: C. albicans or C. parapsilosis cell suspension of $1 \times 10^{6}$ cells $/ \mathrm{mL}$ was prepared in RPMI-1640 to biofilm formation. From prepared standardized suspensions, aliquot of $200 \mu \mathrm{l}$ were added into wells of pre-sterilized, polystyrene, flat-bottom 96-well microtitre plates and incubated statically at $37^{\circ} \mathrm{C}$ for 24 hours.

The preformed biofilms were washed three times with sterile physiological saline in order to remove non-adherent fungal cells. Afterwards, MIC determination was performed in RPMI-1640 with and without 50\% human serum for fluconazole, amphotericin B, caspofungin and micafungin using XTT-assay. In case of $C$. albicans, the examined final concentrations of MIC determinations ranged from $0.015 \mathrm{mg} / \mathrm{l}$ to $32 \mathrm{mg} / \mathrm{l}$ for each tested antifungal agent. For $C$. parapsilosis, the tested concentrations ranged from 0.015 to $32 \mathrm{mg} / \mathrm{l}$ and from 0.015 to $512 \mathrm{mg} / \mathrm{l}$ for amphotericin $B$ and for fluconazole as well as echinocandins, respectively. MICs of sessile cells was defined as the lowest drug concentration resulting at least $50 \%$ fungal damage compared to growth control cells for all antifungals. Susceptibility pattern of biofilms against antifungals was evaluated using metabolic activity based fungal damage assay. Activity was calculated using the following formula: fungal damage $(\%)=[1$-(absorbance of experimental cells $(492 \mathrm{~nm})$ /absorbance of control wells $(492 \mathrm{~nm}))] \times 100$. All isolates were examined in three independent experiments for each tested antifungal drug. The ratio of viable and dead cells was measured in fluorescent microscopic analysis using a LIVE/DEAD® BacLight ${ }^{\text {TM }}$ viability kit.

\section{Results}

\begin{tabular}{|c|c|c|c|c|c|c|c|c|}
\hline \multirow{2}{*}{$\begin{array}{c}\text { Candida } \\
\text { albicans } \\
(\mathrm{n}=10)\end{array}$} & \multicolumn{2}{|c|}{$\begin{array}{l}\text { MICs of planktonic } \\
\text { cells (mg/l) }\end{array}$} & \multicolumn{2}{|c|}{$\begin{array}{l}\text { MICs of planktonic } \\
\text { cells in RPMl-1640 } \\
\text { with } 50 \% \text { human } \\
\text { serum (mg/l) }\end{array}$} & \multicolumn{2}{|c|}{$\begin{array}{l}\text { MICs of biofilms in } \\
\text { RPMI-1640 (mg/l) }\end{array}$} & \multicolumn{2}{|c|}{$\begin{array}{l}\text { MICs of biofilms in } \\
\text { RPMI-1640 with } \\
50 \% \text { human serum } \\
\text { (mg/l) }\end{array}$} \\
\hline & Range & Median & Range & Median & Range & Median & Range & Median \\
\hline FLU & $0.06-0.5$ & 0.25 & $0.25-0.5$ & 0.5 & $0.25-64$ & 32 & $0.015-0.25$ & 0.03 \\
\hline AMB & $0.5-1$ & 1 & $2-4$ & 4 & $0.12-1$ & 0.25 & $0.25-2$ & 0.5 \\
\hline CAS & $0.06-0.25$ & 0.125 & $0.25-0.5$ & 0.5 & $0.03->32^{1}$ & 0.25 & $0.25-2$ & 0.5 \\
\hline MICA & $0.015-0.03$ & 0.015 & $0.5-1$ & 1 & $0.03->32^{1}$ & 0.03 & $0.06-32$ & 2 \\
\hline \multicolumn{9}{|l|}{$\begin{array}{l}\text { Candida } \\
\text { parapsilosis } \\
(n=10)\end{array}$} \\
\hline FLU & $0.125-0.25$ & 0.188 & $0.5-1$ & 1 & $512->512^{2}$ & $>512$ & $0.015-0.06$ & 0.03 \\
\hline AMB & $0.25-0.5$ & 0.5 & $1-4$ & 2 & $0.5-2$ & 1 & $0.015-0.06$ & 0.015 \\
\hline CAS & 1 & 1 & $4-8$ & 8 & $128->512^{2}$ & 384 & $0.015-0.25$ & 0.015 \\
\hline MICA & $0.25-1$ & 1 & $4-8$ & 8 & $128->512^{2}$ & 256 & $0.015-0.25$ & 0.015 \\
\hline
\end{tabular}

Table 1. Minimum inhibitory concentrations (MICs) of fluconazole (FLU), amphotericin B (AMB), caspofungin (CAS), micafungin (MICA) against planktonic cells and biofilms formed by Candida albicans and Candida parapsilosis clinical isolates in the presence and absence of $50 \%$ human serum
1 MIC is offscale at $>32 \mathrm{mg} /, 64 \mathrm{mg} / \mathrm{l}$ (one dilution higher than the highest tested concentration) was used for median calculation 'MIC is offscale at $>512 \mathrm{mg} / \mathrm{ll}, 1024 \mathrm{mg} /$ / (one dilution higher than the highest tested concentration) was used for median calculation
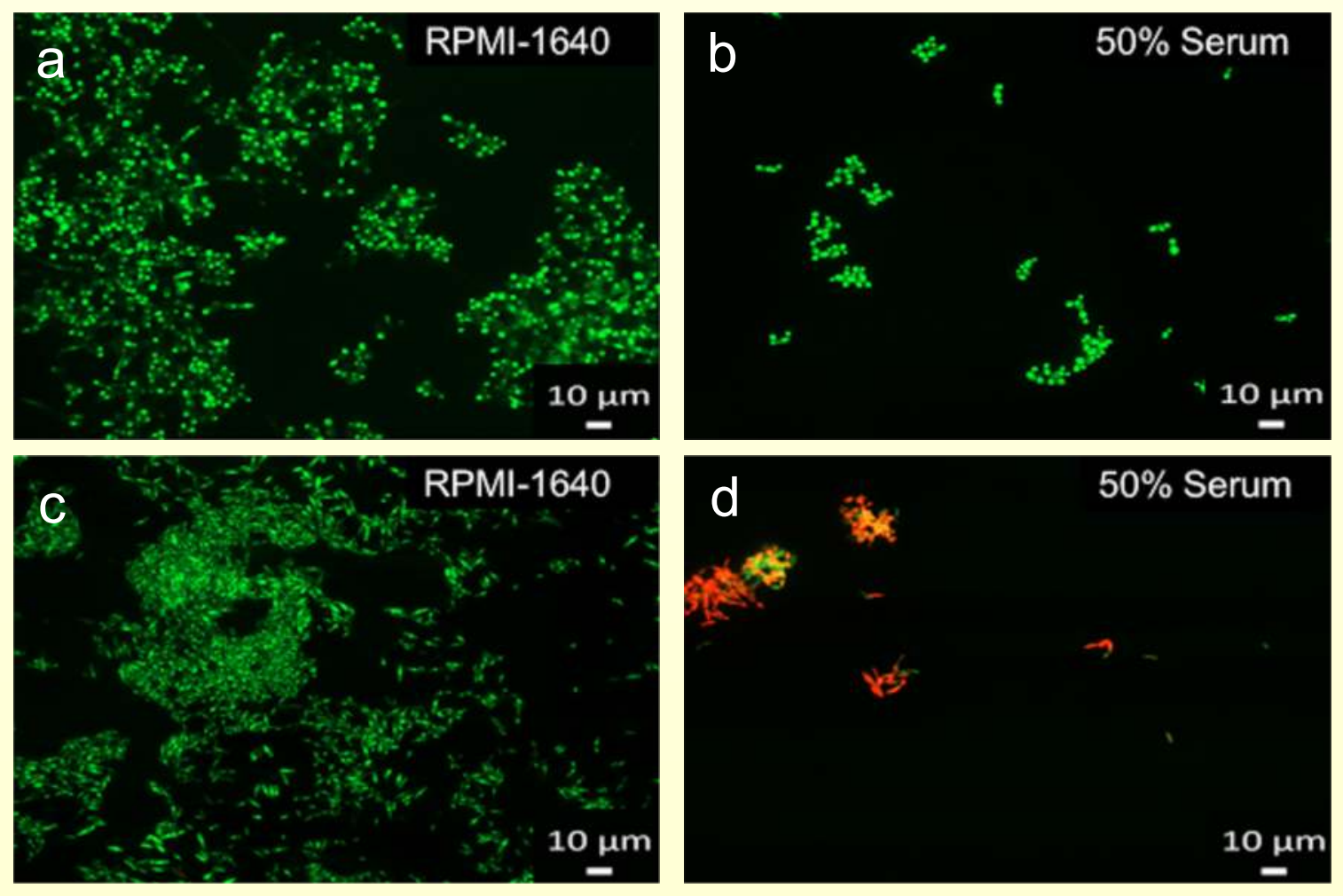

Figure 1. LIVE/DEAD fluorescence imaging of C. albicans (1544) (a, b) and C. parapsilosis (26977) (c, d) Figure 1. LIVE/DEAD fluorescence imaging of $C$. albicans $(1544)(a, b)$ and $C$. parapsilosis $(26977)(c$,
representative isolates in the presence $(b, d)$ or absence $(a, c)$ of $50 \%$ human serum. Live cells (green) and nonviable cells (red) were stained

\section{Conclusions}

1. In serum, the traditionally biofilm-active antifungals (echinocandins, amphotericin B) showed decreased activity against $C$. albicans biofilms due to the high rate of protein binding.

2. C. parapsilosis showed higher susceptibility against the tested antifungals due to the reduced biofilm mass in RPMI-1640 with serum and the observed fungicidal effect exerted by serum.

3. Fluconazole showed high antifungal activity in the presence of $50 \%$ serum both against $C$. albicans and $C$. parapsilosis biofilms. 